\title{
Real Time Implementation of STATCOM to Analyze Transient and Dynamic Characteristics of Wind Farm
}

\author{
Adnan Sattar, Ahmed Al-Durra, and S.M.Muyeen \\ Electrical Engineering Department, The Petroleum Institute, P.O.Box 2533, Abu Dhabi, UAE \\ E-mail: asattar@pi.ac.ae
}

\begin{abstract}
In this paper, a grid connected wind farm with a static synchronous compensator (STATCOM) is modeled in Real Time Digital Simulator (RTDS) environment to analyze its dynamic and transient characteristics in real system. This work is also a part of future power hardware-in-loop (PHIL) test and therefore, individual components are models considering practical viewpoints. Wind turbines and generators of a wind farm, power grid, and control system are realized in the large time-step main network. However, 2-level voltage source converter based STATCOM is modeled in RTDS small time-step environment to adapt with higher switching frequency, where interface transformer is used to link the different time step subnetworks. Suitable control strategy for STATCOM is developed to augment the stability of wind farm considering that capacitor connected at the terminal of wind generator is reduced up to certain percentage. Option for integrating anemometer for dynamic characteristics analysis, difficulties of STATCOM switching schemes for implementing PHIL testing in RTDS environment are discussed. Results are compared with Laboratory standard power system software PSCAD/EMTDC and the advantages of using RTDS in dynamic and transient characteristics analyses of wind farm are also demonstrated clearly.
\end{abstract}

Index Terms - RTDS, STATCOM, Voltage source converter (VSC), wind energy, Fixed Speed Wind Generator (FSWG), PSCAD/EMTDC.

\section{INTRODUCTION}

Recently, the generation of electricity using wind power has received a great deal of interest. As per global wind energy council (GWEC) statics the global wind capacity will reach close to $450 \mathrm{GW}$ by the end of 2015 [1]. It means that more than $50 \%$ of the present installation until 2010 is going to be added to the power grid. Though variable speed wind generator is becoming popular these days, fixed speed wind turbine generator (FSWG) system which uses Induction Generator (IG) as wind generator has still good market value due to its simple, rugged and maintenance free construction. IG has the stability problem same as synchronous generator [2] which can be overcome using different types of flexible alternating current transmission system (FACTS) devices when new wind farms will be commissioned. In addition, some existing wind farm composed of fixed speed wind generator requires to be installed FACTS device at its terminal to meet the recent wind farm grid code requirement during grid fault condition.

Voltage or current source converter based FACTS devices, such as Solid state transfer switch (SSTS), Dynamic
Voltage Restorer (DVR), Unified power flow controller (UPFC), Static Var Compensator (SVC) and Static Synchronous Compensator (STATCOM) have been used for flexible power flow control, secure loading and damping of power system oscillation [3-5]. Among those, STATCOM is a proven VAR compensating device which can be used to augment the dynamic and transient stability augmentation of wind farm [6-8]. In those studies, offline simulation technique is used to model and simulate the entire system. Typically, when performing offline simulation, the objective is to obtain results as fast as possible. The system solving speed depends on available computation power and the system's mathematical model complexity. Offline simulation technique is not suitable for dynamic characteristics analysis of the system where power converter devices are part of the system, especially when detailed switching model is used to model the power converter using high switching frequency.

This study is conducted in real time digital simulation environment using real time digital simulator (RTDS) to perform both transient and dynamic characteristics analysis of wind farm composed of fixed speed wind generator (FSWG), where STATCOM is considered as VAR compensating tool. This study also aims future power hardware-in-loop (PHIL) testing of STATCOM to validate the control scheme as well as determining its optimum capacity that requires stabilizing the wind farm in both transient and dynamic conditions, which necessitates requirement of real wind speed measurement from real sites.

Real time digital simulator (RTDS) is a novel simulation tool for real time simulation, prototype, and hardware-in-loop testing. It can allow physical devices to be connected with it, e.g., in this case study, anemometer for real wind speed measurement, and voltage/current source converters, protection relay, etc. Moreover, it also provides accurate, fast, reliable and cost effective study of power systems with complex High Voltage Alternating Current (HVAC) and High Voltage Direct Current (HVDC) [9-12]. In renewable power sector, the RTDS can extensively be used for advance research work due to its bidirectional input/output handling capacity between RTDS simulation and external devices [13$16]$.

In this work, both dynamic and transient stability of wind farms are analyzed in details using a power system model in which one wind farm composed of fixed speed wind 
generators are connected with the infinite bus. STATCOM modeling and control is implemented in the RTDS/RSCAD environment using small time-step which interact with rest of the components in main network running at large time-step using interfacing transformer. The cascaded control scheme is used as the control method of the STATCOM. The capacity of the wind generator capacitor bank is reduced by 25 percent when STATCOM is connected at wind farm to use the STATCOM in optimum way. The modeling and control of STATCOM are demonstrated in detail including switching scheme of its power switches which is close to the real system as the future goal is conduct some PHIL testing. This will be useful for others conducting research with power electronic and renewable energy. Proposed scheme can maintain the terminal voltage of wind farm at the desired value under randomly changing wind condition and meet the wind farm grid code requirement during network fault condition. The responses are compared with laboratory standard power system simulator PSCAD/EMTDC [17]. Advantages of using RTDS over PSCAD/EMTDC in dynamic and transient stability analyses of wind farm are also demonstrated, in this study.

\section{Real Time Digital Simulator (RTDS)- A BRIEF OVERVIEW}

\section{A. Hardware}

Real time digital simulator hardware is based on the parallel processing architecture and has been designed specially to solve the electromagnetic transient simulation algorithm. RTDS simulator consists of multiple RACKs, each of which consist of both communication and processor cards and are linked by a common backplane. To solve a large power system network, it is possible to split the entire power system into parts and these parts can be solved on the different subsystems or even using different racks on the RTDS simulator. Each rack has an Inter Rack Communication (IRC) card which allows the information to be shared between the different racks of RTDS. This study is carried out on RTDS consist of 3 RACKs.

Each rack has also a Workstation Interface (WIF) card which synchronizes the simulation calculations and communicates between different processor cards, as well as communication between different racks of the RTDS simulator. Also WIF card provides Ethernet communication

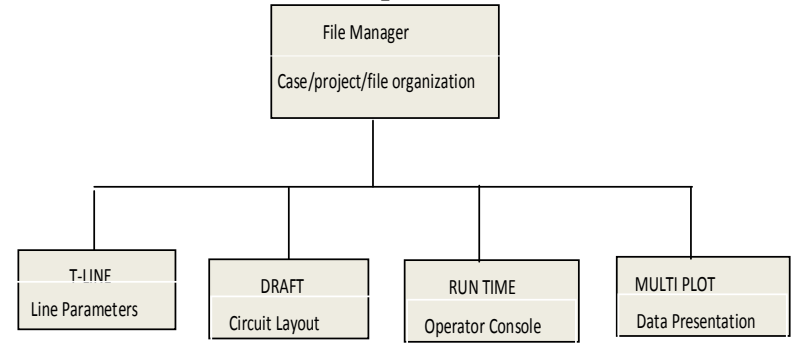

Fig. 1. RSCAD Software Module to and from the graphical user interface during real time simulation.

The processors cards are responsible for the calculation of complete network behavior. RTDS uses two different processor card, 3PC (Processor card) and GPC (Gigabyte processor card). GPC contains 2 RISC processors running at $1 \mathrm{GHz}$. Due to their computational power, they are often used in more than one component model calculation at the same time. It is noted that PB5 processor card, the next generation of GPC card is available in market from 2011, which has additional computation power and communication flexibility.

Besides that, RTDS has a family of GT I/O cards. They are used with the GPC cards. GT I/O cards include analogue and digital input and output with 16-bit data converters. Other physical devices can be connected to the RTDS hardware by GT I/O cards.[10,12]

\section{B. Software}

The graphical user interface between RTDS hardware and user is done by its own software, called RSCAD. It allows simulation circuit to be constructed, run, operated and results to be recorded. The RSCAD has 2 main modules, shown in Fig.1, the Draft and the Run time. In Draft, an extensive library for both power system and control system components is available. The circuit can be constructed by copying the generic components from the library. After completion of the circuit, it will be complied in order to create the simulation codes required by the RTDS simulator. The simulation can be run using RSCAD Run Time module. Run time, operates on a PC or on workstation, back and forth communication with the WIF card through Ethernet. Simulation result can be plotted and operating condition of the system can be changed in run time by using switches, push buttons, etc., like the real world electric control rooms. A special module exists in RSCAD, so called T-LINE module, facilitate entry of transmission line data. Input information is related to the line geometry and conductor type. Multi-plot is used to analyze the graphical results and also to prepare it in report ready format. Several functions are also available e.g Fourier analysis and Total Harmonic Distortion computation. [9-11].

\section{WIND TURBINE MODELING}

The extracted power from the wind turbine can be expressed by the following equation [18]

$P_{w}=0.5 \pi \rho R^{2} V_{w}^{3} C_{p}(\lambda, \beta) \quad[W]$

Power coefficient, $C_{p}$ and tip speed ratio, $\lambda$ can be expressed by the following equations [19],

$$
\begin{aligned}
& C_{p}(\lambda, \beta)=0.5\left(\Gamma-0.02 \beta^{2}-5.6\right) e^{-0.17 \Gamma} \\
& \lambda=\frac{\omega_{r} R}{V_{w}} \\
& \Gamma=\frac{R}{\lambda} \frac{3600}{1609}
\end{aligned}
$$


The turbine torque and torque coefficient are expressed by the following equation

$T_{m}=0.5 \pi \rho R^{3} V_{w}^{3} C_{t}(\lambda)[N M]$

$C_{t}(\lambda)=\frac{C_{p}(\lambda)}{\lambda}$

Where $\rho$ is the air density $[\mathrm{m}], \mathrm{R}$ is the radius of the wind turbine blade $[\mathrm{m}], \mathrm{V}_{\mathrm{w}}$ is the wind speed in $\mathrm{m} / \mathrm{sec}, \beta$ is the pitch angle in degree, $\omega_{\mathrm{r}}$ is the rotational speed in $\mathrm{rad} / \mathrm{sec}$, and $\mathrm{T}_{\mathrm{m}}$ is the wind turbine torque in $\mathrm{Nm}$.

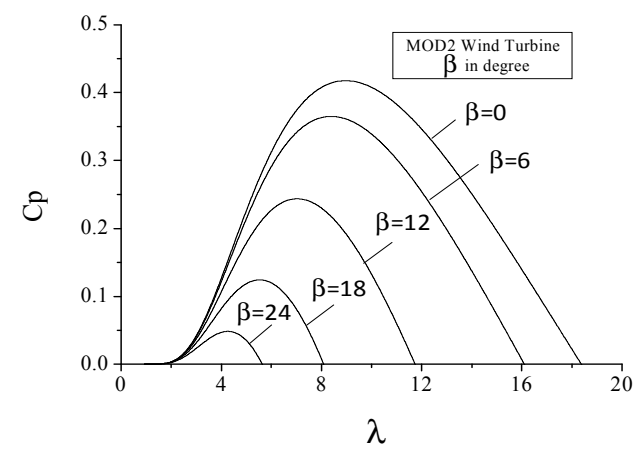

Fig. 2. Cp- $\lambda$ Curve for different pitch angles

The $C p-\lambda$ curves are shown in Fig. 2 for different values of $\beta$. The conventional pitch controller has been used in this study, showed in Fig. 3. The principle of the pitch controller is to keep the output power of wind generator at rated level by controlling the blade pitch angle of turbine blade when the wind speed is above than the rated wind speed.

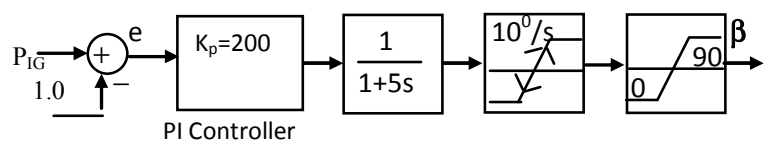

Fig. 3. Conventional Pitch Angle Controller

\section{REAL Time Simulation SETUP}

Fig. 4 shows the real time simulation setup required for this study. As discussed earlier, RTDS can be connected with other physical devices, an anemometer is considered to measure the wind speed data from the real site which will be sent to the RTDS via GT I/O cards. The wind speed signal will then be sent to RSCAD environment though workstation interfacing card and will be used in wind turbine model to produce torque for wind generator. Hence, this is the most accurate way of analyzing the behavior of wind turbine generator behavior at different operating conditions.

Fig. 5 shows briefly the different subsystems used to model grid connected wind farm where STATCOM is connected at the wind farm terminal. Grid synchronization using phase locked loop and control system are also modeled as subsystem. The modeling is completely done in RTDS/RSCAD environment.

In Fig. 6, RTDS modules and the processor assignments has been shown. Main power system components are solved on the 3PC card. The STATCOM has been modeled in the

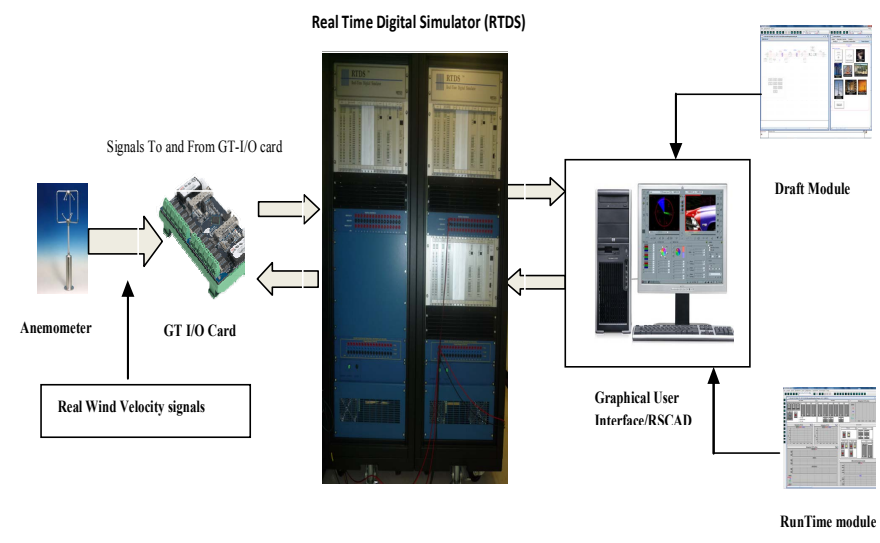

Fig. 4. Simulation Block Diagram

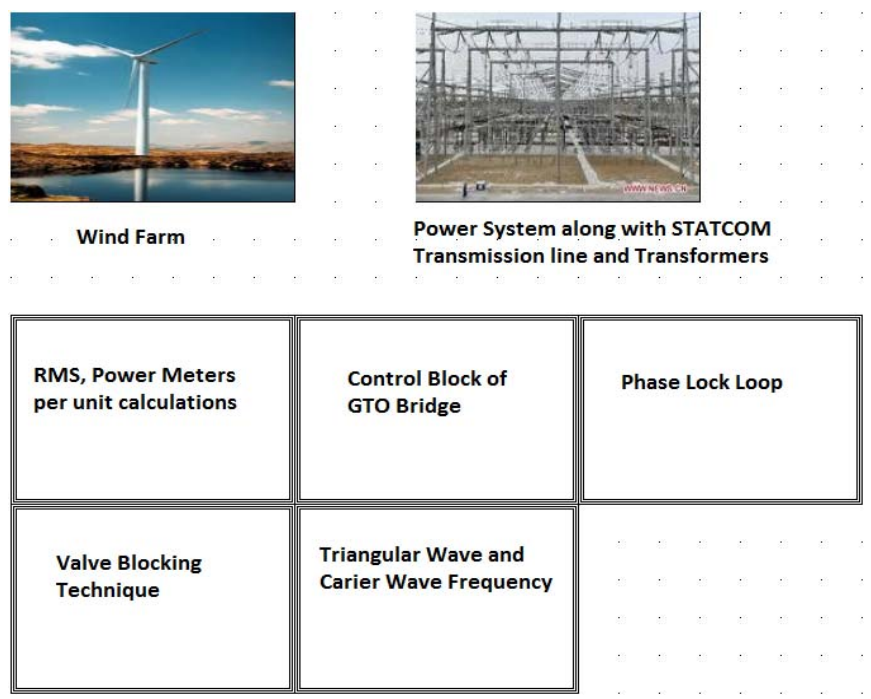

Fig. 5. Modeling of the Fixed Speed wind Turbine Induction Generator in RTDS/RSCAD Environment

Voltage Source Converter (VSC) small time-step network, which are solved on the GPC card. The control part is solved on the 3PC card. Carrier wave signal is generated in the large time-step and are imported in the small timestep after being adapted with small-time step. The carrier wave frequency is chosen $2 \mathrm{kHz}$. Large time-step (typically running at $50 \mu \mathrm{s})$ and small time-step $(1 \mu \mathrm{sec}-$ $4 \mathrm{usec})$ is interfaced via interface transformer.

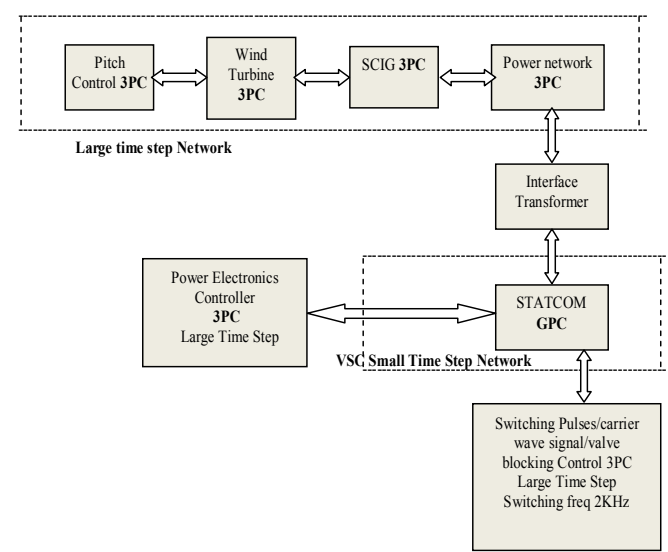

Fig. 6. RTDS Modules and processor assignments for the FSWG 
Wind farm is simulated using aggregated model where many wind generators can be represented with a large wind generator. The parameters of the induction generator used in this study are shown in Table I.

TABLE I

INDUCTION GENERATOR PARAMETERS

\begin{tabular}{|l|l|}
\hline MVA & 10 \\
\hline Rated Phase Voltage (L-N) KV & 0.69 \\
\hline Rated Frequency [Hz] & 50 \\
\hline Stator Resistance, ra [pu] & 0.01 \\
\hline Stator leakage reactance, xa [pu] & 0.1 \\
\hline Unsaturated magnetizing & 3.5 \\
\hline First cage rotor resistance, rfd [pu] & 0.01 \\
\hline First cage rotor leakage reactance, & 0.03 \\
\hline Neutral resistance, rntrl [pu] & $5.0 \mathrm{e} 4$ \\
\hline Inertia constant, H [MWs/MVA] & 3 \\
\hline
\end{tabular}

\section{STATCOM CONTROL STRATEGY}

Fig. 7 shows the modeling of STATCOM in the VSC small time-step network along with the switching components. This section is described below.

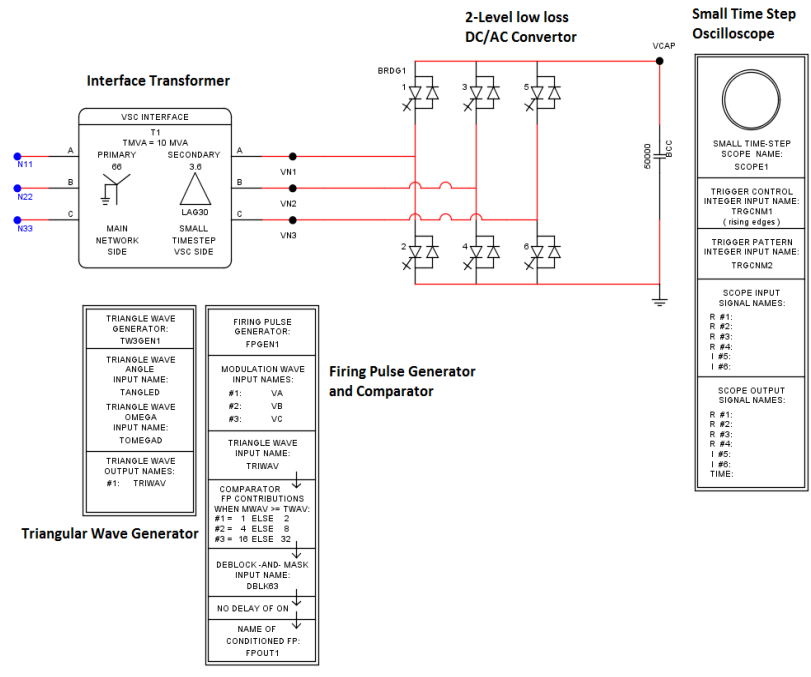

Fig. 7. Modeling of STATCOM in VSC Small time Step

\section{A. Control Scheme}

The control block diagram of VSC based two level STATCOM is shown in Fig. 8 The aim of the control is to maintain desired voltage magnitude at the wind farm terminals during normal operating condition and recover the voltage in shortest possible time after occurrence of grid fault. For the control of VSC, the well-known cascaded vector control scheme is used in the control of STATCOM. The dq quantities and three-phase electrical quantities are related to each other by reference frame transformation. The transformation angle is detected from the three phase voltages $\left(\mathrm{V}_{\mathrm{A}}, \mathrm{V}_{\mathrm{B}}, \mathrm{V}_{\mathrm{C}}\right)$ at the connection point of STATCOM by using phase locked loop (PLL) system. With suitable adjustment of the magnitude and phase of the VSC output voltage, an efficient control of power exchange between the STATCOM and the ac power system can be obtained. The vector control scheme generates the three-phase reference signals which are used to generate the switching signals for the GTO switched STATCOM. The STATCOM rating has been considered as the same of wind farm rating. The rated DC link voltage is $6.6 \mathrm{kV}$. The STATCOM is connected to the $66 \mathrm{kV}$ line by a

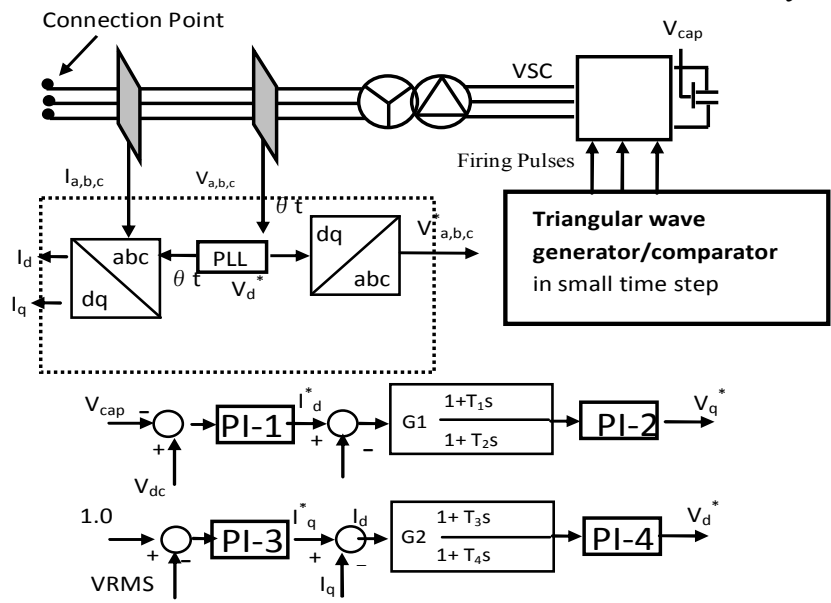

Fig. 8. Control block diagram of VSC based STATCOM

single step down transformer $(66 \mathrm{kV} / 3.6 \mathrm{kV})$ with $0.1 \mathrm{p} . \mathrm{u}$ leakage reactance. The DC-link capacitor value is $50000 \mu \mathrm{F}$.

\section{B. Switching Scheme}

Using the principal of pulse width modulation scheme, the carrier and modulation signals are generated in the RTDS large time-step size environment and then processed to generate high resolution firing pulses using the RTDS firing pulse generator component in the small time-step environment [12]. In order to ensure accurate firing this component requires the transfer of reference phase and frequency from the large time-step environment. This allows the component to extrapolate the phase between large timesteps. The valves of the GTO bridge gets firing pulse input from the comparator by selecting the option CC_WORD of GTO bridge. The valves of the GTO bridge are controlled by the respected bits in a firing pulse word. These consecutive bits are aligned in such a way that the least significant bit (LSB) in the firing pulse coincide with the LSB in the final applied firing pulse word. Hence the first LSB controls the valve 1, the second LSB controls the valve 2 and so on. [12]

\section{SIMULATION RESUlTS}

In this paper, both transient and dynamic characteristics are analyzed when STATCOM is considered to be connected at wind farm terminal, which is the part of future PHIL testing and optimum capacity determination process for STATCOM that suits a wind farm. Keeping in mind the PHIL testing, STATCOM is modeled in small time-step environment. Real wind speed data is measured, stored in data file, and used in RTDS environment using scheduler which will finally be replaced with advanced anemometer 
equipped with remote data logger. Realistic data is used in transmission line calculated from transmission line length which can be changed suitably with any wind farm site data in the next step. Line length is important because STATCOM voltage support set point is considered at the common coupling point. Results are also compared with PSCAD/EMTDC where time step is considered as $20 \mu \mathrm{sec}$ and switching frequency is considered as $1000 \mathrm{~Hz}$. Detailed switching model is considered to model STATACOM in PSCAD/EMTDC environment to perform the time comparison.

\section{A. Dynamic Characteristics Analysis}

In this case study, dynamic characteristics of the wind farm are analyzed using real wind speed data without incorporating interpolation technique in both PSCAD/EMTDC and RTDS/RSCAD environment. The analysis is carried out using $50 \mathrm{sec}$ of wind speed data. Longer period can be considered based on the available memory resources. As the wind speed is changing randomly, the wind farm terminal voltage cannot be maintained at constant value using only the capacitor bank of rated capacity as shown in Fig. 9. In Fig. 9, step change around $10 \mathrm{sec}$ represents the change of machine state from constant speed to normal operation. When STATCOM is used, even using a $25 \%$ reduced capacitor bank, terminal voltage of wind farm can be maintained at the desired level set by Transmission System Operators (TSOs), as shown in Fig. 10. Both Figs. 9 and 10 are obtained from RTDS simulation.

A time comparison is carried out for the simulation in both PSCAD/EMTDC and RTDS/RSCAD. In RTDS large and small time step were carried out using $40 \mu \mathrm{sec}$ and $1.5 \mu \mathrm{sec}$ respectively and a total of $59 \mathrm{sec}$ is required to run and plotting the curves to simulate $50 \mathrm{sec}$ of natural response. However, in PSCAD/EMTDC a total time of $720 \mathrm{sec}$ is required to finish the run, though the program is simulated using $20 \mu \mathrm{sec}$. Therefore, it is quite difficult to perform
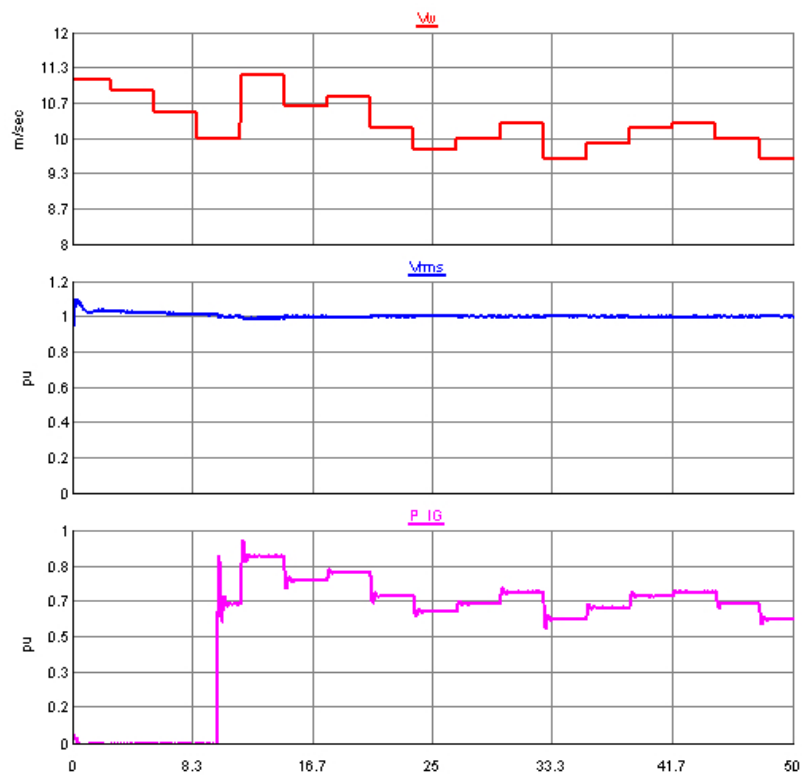

Fig. 9. Responses using capacitor bank at Rated Capacity

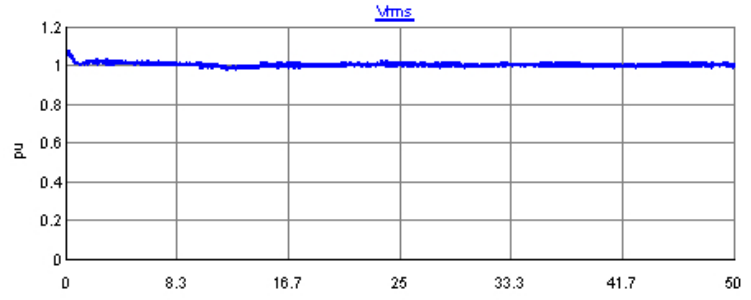

Fig. 10. Wind farm terminal voltage considering STATCOM and 25\% reduced capacitor bank

dynamic analysis for longer time in the range of hour or day to determine the optimum capacity of STATCOM suitable for a real wind farm or other types of analysis, which requires the program to be run for long time. RTDS is also suitable for dynamic characteristics analysis because it can interact with real hardware, which is not possible in the case of other power system software such as PSCAD/EMTDC, MATLAB/Simulink, PSS, etc.

\section{B. Transient Characteristics Analysis}

In this case study, transient stability analysis of wind farm is carried out following the wind farm grid code requirement [21] using both PSCAD/EMTDC and RTDS/RSCAD. It is assumed that wind speed is kept constant at rated speed, as assumed that the speed of the wind does not change greatly within the small time duration considered. A $150 \mathrm{msec}$ 3LG fault is applied on the sending end of one transmission line. Fig. 11 shows the terminal voltage and IG rotor speed responses using RTDS when only rated capacitor bank is considered. It is seen that without additional reactive power support wind farm grid code cannot be maintained. Fig. 12 and 13 show the responses of IG real power, STATCOM reactive power, terminal voltage at the wind farm, DC link capacitor voltage, and the IG rotor speed using RTDS/RSCAD and PSCAD/EMTDC, respectively. PSCAD/EMTDC takes 3 minutes to finish the simulation time of $10 \mathrm{sec}$, while RSCAD/RTDS requires only $5.0 \mathrm{sec}$. The results shows good agreement in both simulation environment, however, RTDS can be effectively use to find out critical clearing time for any network using optimization technique due to it very fast computational power.

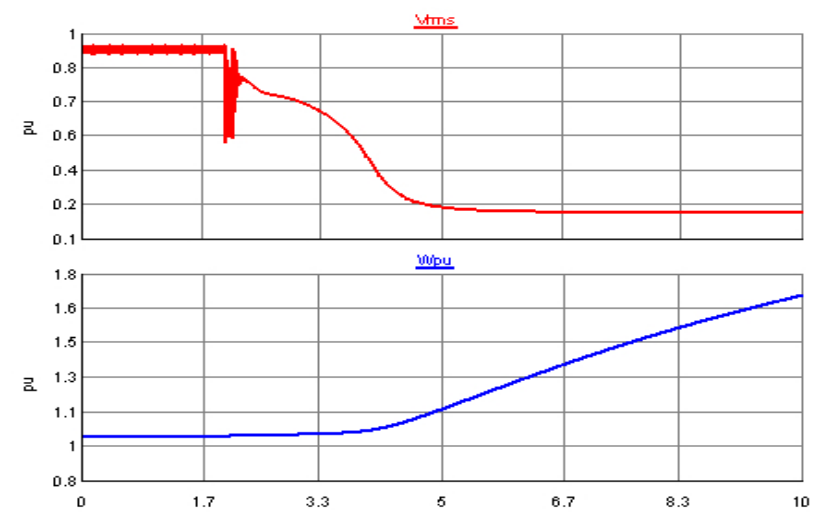

Fig. 11. Transient responses without STATCOM (3LG fault) 

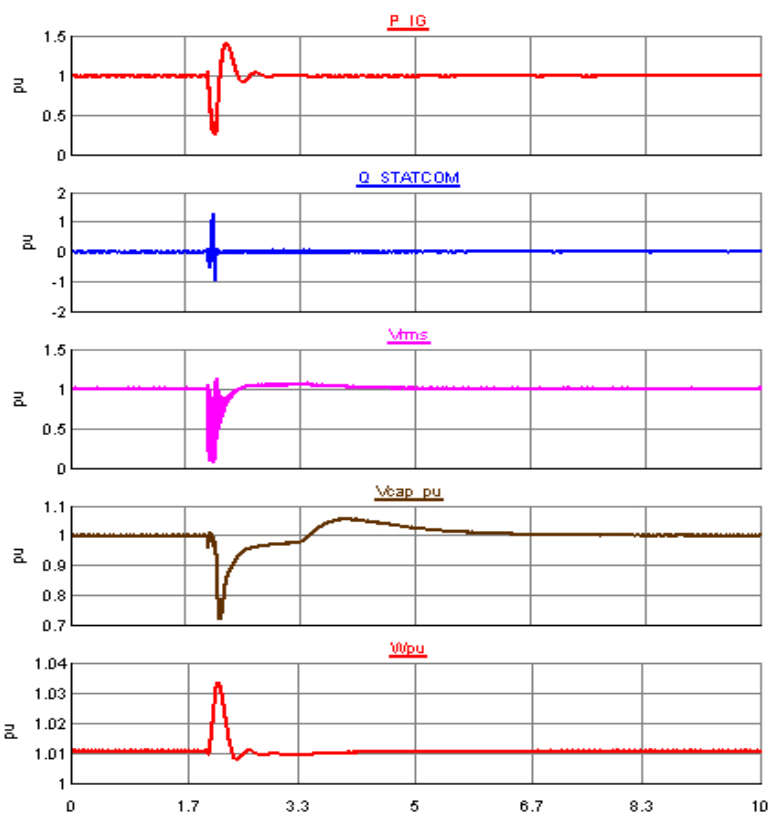

Fig. 12. RTDS responses of FSWT using STATCOM (3LG fault)

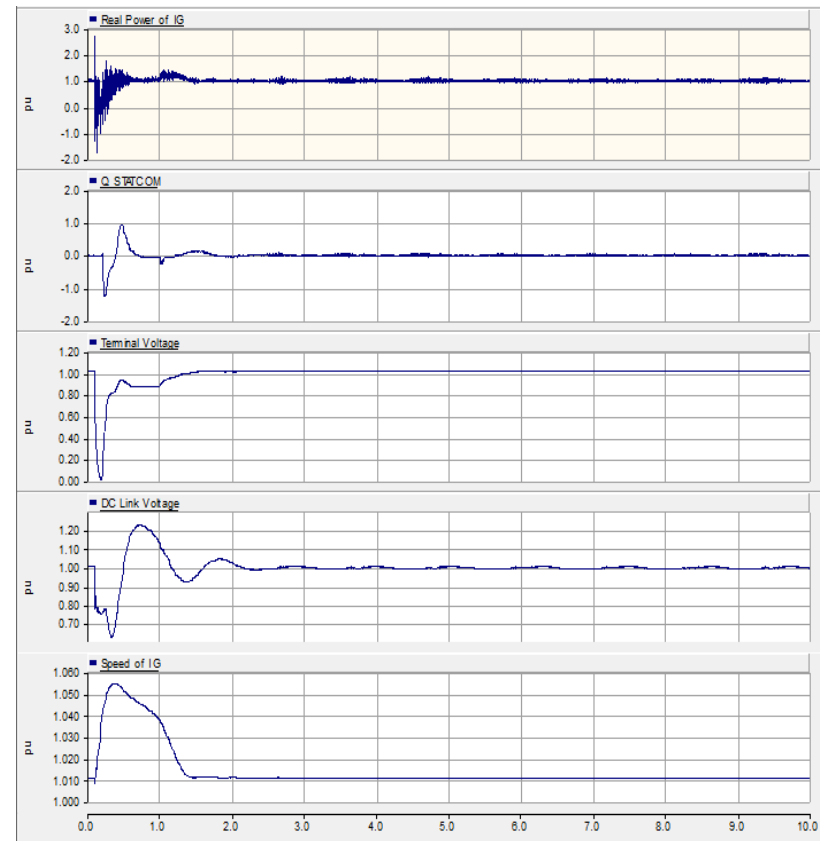

Fig. 13. PSCAD responses of FSWT using STATCOM (3LG fault)

\section{CONCLUSION}

In this study, a precise model for complete grid connected wind farm connected with STATCOM is carried out using real time power system simulator, RTDS/RSCAD environment. The modeling of STATCOM is done in small time-step, which could be used any power hardware-in-loop test. The option of integrating real wind speed data with the simulation is kept open in the modeling to interact with real wind farm site using advanced anemometer equipped with remote data logger. It is found that the implemented control scheme can maintain the wind farm terminal voltage at the desired level in both normal and grid fault condition. It is also reported that RTDS is an effective tool to conduct transient and dynamic analysis of wind farm, other renewable energy sources, micro-grid, etc due to fast computation in real time and external hardware interfacing capability.

\section{ACKNOWLEDGEMENT}

The authors would like to acknowledge "Electric Machine Laboratory" of KITIMI INSTITUTE OF TECHNOLOGY, JAPAN for giving the permission to use the wind speed data in this work.

\section{REFERENCES}

[1] The Global Wind Energy Council, "Global Wind Report-Annual Market Update, 2010,” March 2011, [Online], http://www.gwec.net/

[2] Claudio L.Souza et. al., "Power System Transient Stability Analysis including Synchronous and Induction Generator," IEEE Porto Power Tech Proceedings, Vol.2, pp.6, 2001

[3] Dr.L.Gyugyi, "Unified Power-Flow Control Concept for Flexible AC Transmission Systems,” IEE Proc.-C, Vol.139, No.4, pp.323-331, 1992.

[4] Laszlo Gyugyi, "Dynamic Compensation of AC Transmission Lines By Solid-State Synchronous Voltage Sources," IEEE Trans. On Power Delivery, Vol.9, No.2, pp.904-911, 1994.

[5] H.F.Wang, F.Li, and R.G.Cameron, "Facts Control Design Based on Power System Nonparametric Models," IEE Proc.-Generation Transmission and Distribution, Vol.146, No.5, pp.409-415, 1999.

[6] S. M. Muyeen, H. M. Hasanien, R. Takahashi, T. Murata, and J. Tamura, "Integration of Space Vector PWM Controlled STATCOM with Wind Farm Connected to Multi-Machine Power System," J. Renewable Sustainable Energy (JRSE), Vol.1, Issue.1, Article No. 013103, 2009.

[7] Saad-Saoud Z., "Application of STATCOMs to Wind Farms," IEE Proc. Generation Transmission and Distribution, Vol.145, No.5, pp.511-517, 1998.

[8] S. M. Muyeen et al., "Stabilization of Grid Connected Wind Generator by STATCOM," International Conference on Power Electronics and Drive Systems (IEEE PEDS 2005), Conference CDROM, pp. 1584-1589, Malaysia, 2005

[9] P. Forsyth, R. Kuffel, “ Utility Applications of a RTDS Simulator, ” 2007 IPEC International Power Engineering Conference, pp. 112- 117, Dec 2008.

[10] Kuffel, J. Giesbrecht, T. Maguire, R. P. Wierckx, P. A. Forsyth, and P. G. Mclaren, " RTDS- A Fully Digital Power Simulator Operating in Real Time, " 1995 WESCANEX Conference Proceedings on Communications, Power, and Computing, pp. $300-305$, May 1995.

[11] R. Kuffel, J. Giesbrecht, T. Maguire, R. P. Wierckx, P. A. Forsyth, and P. G. Mclaren, " A Fully Digital Real-Time Simulator for Protective Relay Testing, " 1997 Developments in Power System Protection, Sixth International Conference, pp. 147- 150, Mar 1997.

[12] Real Time Digital Simulator Power System and Control User Manual, RTDS Technologies, 2009

[13] D.-J. Park, Y.-J. Kim, M.H. Ali, M. Park, I.-K. Yu, "A Novel Real Time Simulation Method For Grid-Connected Wind Generator System by Using RTDS," 2007 ICEMS international conference on Electrical Machines and Systems, pp.1936 - 1941, Oct. 2007

[14] G. Wang, W. Gao, "Real Time Simulation For Wind Power Generation System Using RTDS” NAPS '08. Power Symposium, pp.1 - 6, Nov 2009.

[15] I. J. V. Vliet, A. M. V. Voorden, P. H. Schavemaker, G. C. Paap, and L. V. D. Sluis, "Real-Time Implementation to Study the Impact of Renewable Energy in Power Systems," 2005 International conference on Future Power Systems , pp. 1 - 6, Mar. 2006.

[16] G. Byeon, C. S. Song, S. Oh, I. -K. Park, and G. Jang, "An Implementation of Grid-Connected DFIG Wind Power Generation System using RTDS,"

[17] PSCAD/EMTDC Manual, Manitoba HVDC Research Center, 1994.

[18] S. Heier, Grid Integration of Wind Energy Conversion System, Chicester, UK, John Wiley \& Sons Ltd., 1998.

[19] O.Wasynczuk et.al. , "Dynamic Behavior of a Class of Wind Turbine Generators During Random Wind Fluctuations," IEEE Transactions on Power Apparatus and Systems, Vol.PAS-100 ,No.6, pp.2837-2854,1981.

[20] L. Qi, J. Langston, M. Steurer, A. Sundaram, "Implementation and Validation of a Five-Level STATCOM Model in the RTDS small time-step Environment, ” 2009 PES Power \& Energy Society General Meeting, pp. 1 -6 , Jul 2009.

[21] E.On Netz, Grid Code, High- and Extra-High Voltage, April 2006, available at www.eon-netz.com/ 